\title{
Stranding Cycling Transit Users on Los Angeles' Orange Line Bus Rapid Transit
}

\author{
Craig T. Olwert \\ California State University, Northridge \\ Jose Tchopourian \\ Los Angeles Department of Transportation \\ Vicente O. Arellano, Mintesnot Woldeamanuel \\ California State University, Northridge
}

\begin{abstract}
The Los Angeles Metro Orange Line is a bus rapid transit (BRT) system that accommodates cycling transit users (CTU) with front-of-the-bus mounted bike racks. However, cyclists sometimes find these bike racks full and are stranded until the arrival of the next bus. By collecting CTU usage data at seven Orange Line stations, the following results were observed: (1) CTUs are more likely to be stranded during weekday nights due to the proximity to three major colleges; on weekends, CTUs are more likely to be stranded in the mornings; (2) Metro's policy that increased evening service during 2013 successfully decreased the number of stranded cyclists; and (3) when the racks are two-thirds full, approximately 20 percent of buses will strand at least one cyclist.
\end{abstract}

\section{Introduction}

Bus rapid transit (BRT) has proven to be a popular alternative to rail-based transit, particularly for its cost effectiveness and the minimal time to build and start operations. BRT frequently is associated with Curitiba (Brazil), where it started in the 1970s as a lower capital alternative to light rail and subways (Duarte and Rojas 2012). This type of mass transit has since become more widespread throughout the world. While elements of BRT have been adopted by seemingly every local transit agency in the United States and Canada, the Institute for Transportation and Development Policy's (ITDP) BRT Standard (2014) excludes most bus systems in the United States that purport to be BRT. The standard is based on accumulation of points for features present in an ideal BRT system, with high-scoring systems distinguished with Gold, Silver, or Bronze status. Common elements of BRT include a dedicated busway, pre-boarding fare collection, high-quality station 
amenities, and bus headways similar to rail transit. Further, elements often are related to branding or imagery, including the BRT vehicles themselves being of distinctive designs and transit system maps elevating BRT lines to rail status. Within these criteria, only four BRT lines in the U.S. have ITDP designation: Cleveland, Ohio (Silver); Los Angeles Metro Orange Line (Bronze); Eugene, Oregon (Bronze); and San Bernardino, California (operational as of April 2014 and not assessed yet). Boston's Silver Line excluded some planned elements and did not receive ITDP BRT status.

Cycling transit users (CTUs) are multimodal users of public transit (including BRT) that use their bicycles at one or both access/exit points of the transit system. It has generally been understood that CTUs are found most frequently in suburban areas (Krizek and Stonebraker 2010; Bachand-Marieau et al. 2011) because transit stations are less frequent in these low-density areas. CTU demographics have changed from being white, well-educated homeowners in single-family housing in 2001 to a more heterogeneous mix. By 2009, race was the only statistically-significant difference between CTUs (Wang and Liu 2013). However, even race may become less important as "invisible riders"-immigrants from Latin America who use bicycles because of affordability issues-increase in central city populations (Koeppel 2006). Understanding the changing face of CTUs will help transit agencies better manage their experience.

Transit agencies support integrating bicycle-transit travel in the United States as a method to increase transit ridership (Wang and Liu 2013). Biking extends the catchment area of transit stops far beyond walking range. A study of Portland's Westside Express suburb-to-suburb commuter rail found that the median walking distance was 0.54 miles, whereas the median and mean cycling distances were 1.7 and 2.6 miles, respectively (Bergman et al. 2011). Accommodating cyclists is a lower-cost option compared to feeder-buses and automobile park-and-ride facilities (Krizek et al. 2011). Other benefits to increasing transit usage, with increased CTU ridership as a portion, include reducing greenhouse gas (GHG) emissions and creating a more active public. Vincent and Jerram (2006) estimated that BRT would be the most effective method to decrease carbon dioxide emissions from a hypothetical medium-sized U.S. city versus the base bus and private vehicle cases and even compared to adding a light rail system. Wener and Evans (2007) found that train commuters walked 30 percent more steps per day than car commuters.

To promote bicycle access to transit services, local bus agencies in the United States have installed bike racks on the front of most transit buses in the U.S. (Hagelin 2005). However, the same trend is not found with BRT, with transit agencies preferring to accommodate CTUs by providing bike sharing, bike racks, and bike lockers at stations rather than allowing cyclists aboard BRT vehicles. This is true in Europe (Martens 2004) as well as most of the U.S. Transit agencies prefer to accommodate CTUs at stations for multiple reasons, including passenger safety, space limitation, length limitations, and to decreased stop time. A bicycle that is held on a bus and not on a rack is a liability that might hurt other passengers, and this problem compounds as the buses become more crowded. Because on-board bicycle racks take away several seats, as ridership levels increase, transit agencies prefer external bike racks (Hillmer, personal communication, 2014). Transit agencies also may face vehicle length limitations, the case in California, so that front-of-the-bus racks can be only so long and additional racks cannot be added to the back of the vehicle. 
Finally - and perhaps one of the largest considerations for transit agencies-bikes can take a while to load or off-load from the bicycle racks (Krizek and Stonebraker 2010), which increases dwell time at stations and reduces the performance of BRTs.

Although transit agencies prefer to accommodate CTUs with fixed infrastructure at stations, riders prefer to bring their bicycles with them (Pucher and Buehler 2009; Krizek et al. 2011). In Montreal, 45 percent of 1,432 survey respondents identified allowing bicycles on board buses as the best method to increase bicycle/transit shares (Bachand-Marieau et al. 2011). Hagelin (2005) found that 26 percent of bike-on-bus users indicated a major problem was full bike racks on buses when looking at 11 Florida transit agencies and 4 non-Florida agencies and their bus systems. Increased cycling accommodation aboard buses seems likely to increase CTU ridership.

Counting the number of CTUs is difficult, and counting the number of stranded CTUs is more difficult. Transit agencies regularly estimate ridership numbers by using actual farebox counts and performing field counts. Field counts usually are performed in two ways: all-day counts at a few stations and rush-hour counts at a larger number of stations. These are then extrapolated to determine counts at all locations and times (Hummer 1994). However, most do not estimate bicycle ridership, and only the Cleveland Metropolitan Transit Authority keeps track of bicycle ridership on its buses (Flamm 2013). Bicycle ridership is likely to be extrapolated from regular transit trends, but with such users as "invisible riders," CTUs may not have the same use patterns. The literature does not indicate that transit agencies count the number of stranded CTUs.

Even with the exterior bicycle racks to accommodate CTUs, the local transit agency in Los Angeles County, commonly known as Metro, struggles to provide adequate bicycle capacity aboard its BRT service known as the Orange Line. Many cyclists are being left behind on the Orange Line due to full bike racks, with more left behind during weekday evenings and weekend mornings. Metro added more evening buses to the Orange Line's 2013 schedule to better accommodate the CTUs. This paper discusses (1) CTU usage patterns and how they differ from pedestrian users, (2) the effectiveness of the added buses in reducing stranded cyclists, and (3) an evaluation of the relationship between the utilization of on-board bus racks and the number of stranded cyclists.

The paper is organized as follows. The next section discusses the history of Metro Orange Line. The data and descriptive statistics follow in the next sections. Analysis of the CTU usage patterns, increased BRT service effects, and the relationship between bike rack utilization and stranded cyclists follows. Finally, the paper ends with conclusions and recommendations.

\section{Background of LA Metro's Orange Line}

The Orange Line is the only full-fledged BRT system in Los Angeles, despite the Metro Rapid service having some BRT elements (Cervero et al. 2013), because it has a dedicated exclusive busway and pre-boarding fare collection. The Orange Line serves the San Fernando Valley, a broad inland suburbanized area northwest of downtown Los Angeles and Hollywood (see Figure 1). The line's area of service is notable for not directly connecting with the city center, but connecting to Amtrak and commuter rail at the western 
Chatsworth terminus and the Los Angeles Metro Red Line (subway) at the eastern North Hollywood terminus. The line runs through a mix of older suburban areas of Los Angeles and passes by three major education institutions. Two campuses of the Los Angeles Community College District-Valley College, with enrollment of 18,789 students, and Pierce College, with 20,506 students-are along the Orange Line, and California State University, Northridge, with an enrollment of 36,911 students, is 4 miles from the Orange Line, connecting via the Reseda station (U.S. Department of Education 2013). These large colleges provide many possible CTUs, supporting the understanding of the demographic profile change of CTUs.

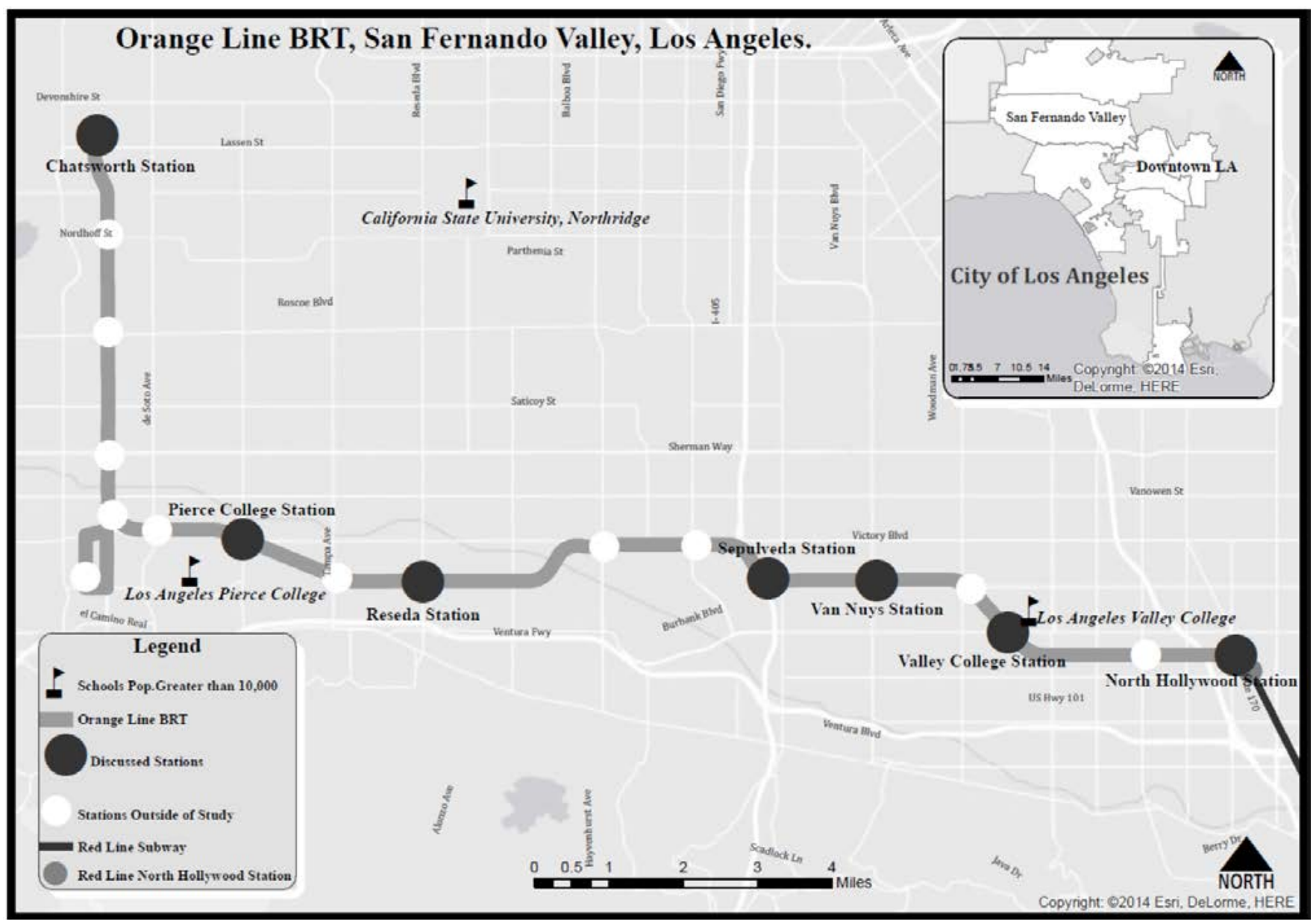

FIGURE 1. Orange Line BRT stations included in study

The Orange Line is noted for its multimodal capture, particularly of cyclists (Vincent and Callaghan 2007; Hensher and Thomas 2008), because it has good access to bike routes (including being paralleled by a Class I bike path), has both bike racks and lockers at stations, and accommodates bicycles on vehicles using exterior racks. In comparison, Curitiba and Bogota's world-famous BRT systems have poor bicycle access, with only 6 of Curitiba's 22 terminals being reached by bicycle paths and 8 of 13 in Bogota (Duarte and Rojas 2012). The Orange Line is similar to transit systems in Europe, in that there are facilities such as guarded bicycle parking and racks (Martens 2004). Where the Orange 
Line exceeds is that it includes on-vehicle racks. These combined improvements increase the use of bicycles as a feeder mode to transit (Martens 2004) and are part of the wider multimodal alternative to private cars (Hine and Scott 2000).

The Orange Line opened in October 2005 and quickly exceeded expected ridership figures. Metro had projected ridership of 5,000-7,500 average weekday boardings for the first year of service, but was serving more than 21,000 average weekday boardings within 6 months of operations (Vincent and Callaghan 2007). Ridership has continued to grow and experienced a growth spurt between 2011 and 2012 when the Orange Line was extended north to reach the Chatsworth station, especially affecting the stations closer to Chatsworth (Reseda and Pierce College) (see Figure 2).

\section{FIGURE 2.}

Daily westbound ridership for selected Orange Line stations

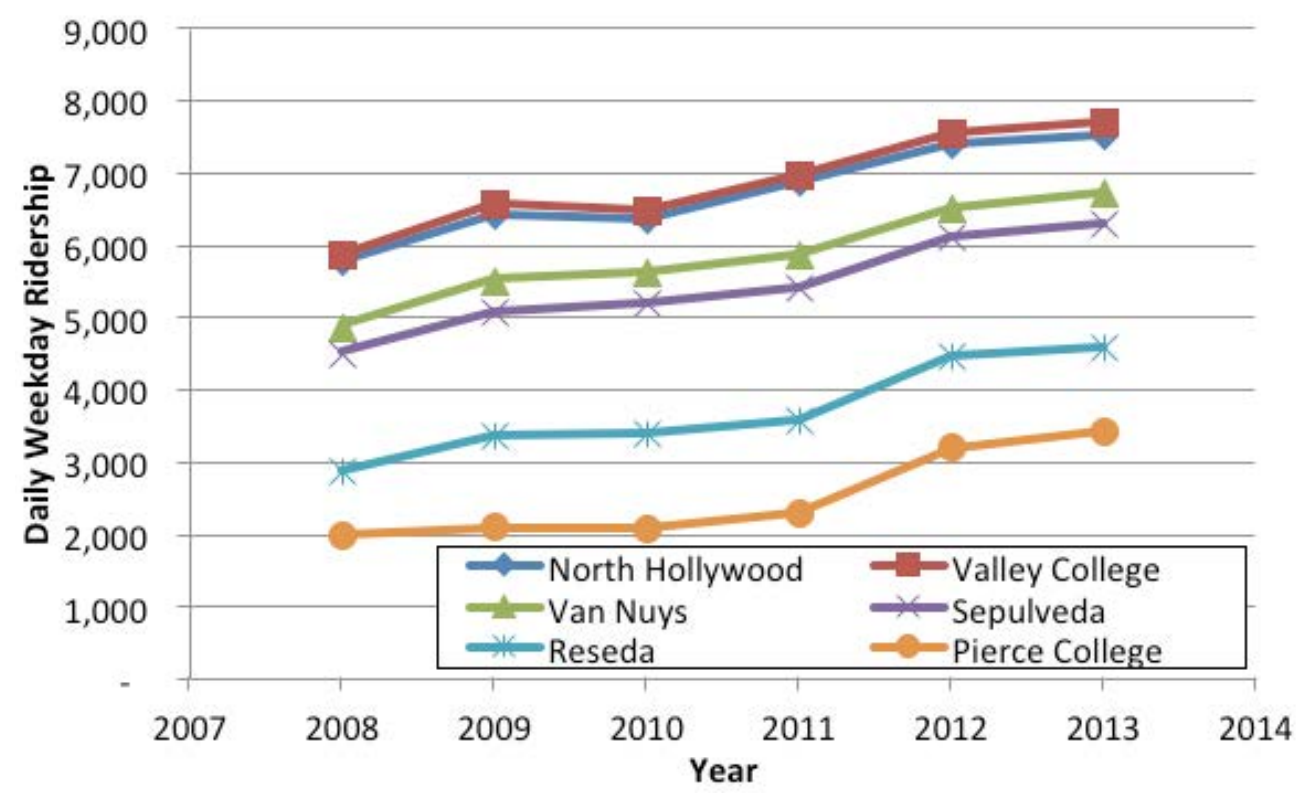

Originally, Orange Line buses met cycling demand with on-board interior bike racks, but because of high pedestrian ridership levels, they were removed to add seating. Racks were placed on the front of buses and quickly were expanded from two to three slots because of continued increases in CTU ridership. Despite the larger racks, cyclists were being left behind because the bus racks were full. An impediment to increasing interior or exterior bike rack capacity is the California Department of Transportation regulation limiting bus vehicle length to 60 feet (CA Vehicle Code $35400 \mathrm{sec}$ B-3).

With limitations in accommodating cyclists on the Metro Orange Line, the sight of cyclists being forced to wait for the next bus became more common to casual observers. This pattern of occurrences prompted our original 2012 research to determine the mismatch between demand for bike rack space and supply of bike slots. Metro increased service during evening hours because it also was aware of stranded CTUs and, with high enough overall evening ridership issues, could justify the increased service. While Metro considered allowing bicycles aboard the buses, safety concerns could be met only by removing permanent seating, which was not considered a viable option (Hillmer, personal communication, 2014). 


\section{Methodology and Data}

In 2012, data were collected for two-hour periods during weekday evenings (Tuesday to Thursday) at the North Hollywood, Van Nuys, Sepulveda, Reseda, and Pierce College station. For 2013, the sampling was expanded to include the Valley College and Chatsworth stations for both weekends and weekdays (Tuesday through Thursday) and included more time periods. As Table 1 shows, more complete collection was obtained at North Hollywood and the Van Nuys station to better understand overall cyclist behavior through the course of a day.

TABLE 1.

Sampling

Collected by

Station and Time

of Day

\begin{tabular}{|c|l|c|c|c|c|c|c|c|}
\hline Effort & \multicolumn{1}{|c|}{ Hours } & $\begin{array}{c}\text { North } \\
\text { Hollywood }\end{array}$ & $\begin{array}{c}\text { Valley } \\
\text { College }\end{array}$ & $\begin{array}{c}\text { Van } \\
\text { Nuys }\end{array}$ & Sepulveda & Reseda & $\begin{array}{c}\text { Pierce } \\
\text { College }\end{array}$ & Chatsworth \\
\hline 2012 & $8: 30$ PM-10:30 PM & D & & D & D & D & D & \\
\hline \multirow{5}{*}{2013} & $6 \mathrm{AM}-8 \mathrm{AM}$ & $\mathrm{D} / \mathrm{E}$ & $\mathrm{D} / \mathrm{E}$ & $\mathrm{D} / \mathrm{E}$ & $\mathrm{D}$ & $\mathrm{D} / \mathrm{E}$ & $\mathrm{D} / \mathrm{E}$ & $\mathrm{D} / \mathrm{E}$ \\
\cline { 2 - 10 } & $8 \mathrm{AM}-10 \mathrm{AM}$ & $\mathrm{D} / \mathrm{E}$ & & $\mathrm{D} / \mathrm{E}$ & & & & \\
\cline { 2 - 10 } & $10 \mathrm{AM}-12$ noon & $\mathrm{D} / \mathrm{E}$ & & $\mathrm{D} / \mathrm{E}$ & & & & \\
\cline { 2 - 10 } & 12 noon-2 PM & $\mathrm{D} / \mathrm{E}$ & $\mathrm{D} / \mathrm{E}$ & $\mathrm{D} / \mathrm{E}$ & $\mathrm{D}$ & $\mathrm{E}$ & $\mathrm{D} / \mathrm{E}$ & $\mathrm{D} / \mathrm{E}$ \\
\cline { 2 - 9 } & $2 \mathrm{PM}-4 \mathrm{PM}$ & $\mathrm{D} / \mathrm{E}$ & & $\mathrm{D} / \mathrm{E}$ & & & & \\
\cline { 2 - 9 } & $4 \mathrm{PM}-6 \mathrm{PM}$ & $\mathrm{D} / \mathrm{E}$ & $\mathrm{D} / \mathrm{E}$ & $\mathrm{D} / \mathrm{E}$ & $\mathrm{D}$ & $\mathrm{D} / \mathrm{E}$ & $\mathrm{D} / \mathrm{E}$ & $\mathrm{D} / \mathrm{E}$ \\
\cline { 2 - 10 } & $6 \mathrm{PM}-8 \mathrm{PM}$ & $\mathrm{D} / \mathrm{E}$ & & $\mathrm{D} / \mathrm{E}$ & & & & \\
\cline { 2 - 10 } & $8 \mathrm{PM}-10 \mathrm{PM}$ & $\mathrm{D} / \mathrm{E}$ & $\mathrm{D} / \mathrm{E}$ & $\mathrm{E}$ & $\mathrm{D}$ & $\mathrm{D} / \mathrm{E}$ & $\mathrm{D} / \mathrm{E}$ & $\mathrm{D} / \mathrm{E}$ \\
\cline { 2 - 9 } & $10 \mathrm{PM}-11 \mathrm{PM}$ & $\mathrm{D} / \mathrm{E}$ & $\mathrm{D} / \mathrm{E}$ & & $\mathrm{D}$ & $\mathrm{D} / \mathrm{E}$ & $\mathrm{D} / \mathrm{E}$ & $\mathrm{D} / \mathrm{E}$ \\
\hline
\end{tabular}

Note: $D=$ week $(D) a y ; E=$ week $(E)$ nd

In 2012, data were collected in 20-minute increments and included number of buses, direction of the buses, number of empty slots leaving the station, and number of cyclists left behind. For 2013, the methodology was slightly revised so that data were collected for each bus: time of arrival, direction, number of bikes arriving, number of bike alighted, number of bikes loaded, number of bikes leaving, and whether a cyclist was left behind by the bus. The improved methodology increased our ability to check and analyze the data. The data were collected between October 24 and November 8, 2012, and from October 16 to December 12, 2013.

\section{Descriptive Statistics}

A total of 2,102 buses were counted in 2013. However, some arrived outside the official time ranges, and others did not have departures: North Hollywood eastbound is the end of the line, so all riders must alight, and boarding begins when the bus starts its westbound trip. Similarly, the Chatsworth station is the western end, so there are only western alightings and no boardings. Of the remaining 1,704 buses counted during the 2013 effort, a total of 70 left a cyclist behind (4.1\%). From the sample, 2,168 slots were full upon departure from the stations out of 5,104 available slots, a utilization rate of 42.5 percent. The results of percent cyclists left behind and slots full on departure are shown in Table 2. 
TABLE 2. Percentage of Buses Stranding at Least One Cyclist and Percentage of Slots Full When Bus Is Departing

\begin{tabular}{|c|c|c|c|c|c|c|c|c|c|c|c|c|}
\hline \multirow[b]{2}{*}{ Day } & \multirow[b]{2}{*}{ Direction } & \multirow[b]{2}{*}{ Station } & \multicolumn{5}{|c|}{ Buses Leaving Cyclists Behind } & \multicolumn{5}{|c|}{ Slots Full on Departure } \\
\hline & & & $\begin{array}{c}6 \mathrm{AM}- \\
8 \mathrm{AM}\end{array}$ & $\begin{array}{c}12 \text { noon - } \\
2 \text { PM }\end{array}$ & $\begin{array}{c}4 P M- \\
6 P M\end{array}$ & $\begin{array}{l}8 P M- \\
10 P M\end{array}$ & $\begin{array}{c}10 \mathrm{PM}- \\
11 \mathrm{PM}\end{array}$ & $\begin{array}{l}6 \mathrm{AM}- \\
8 \mathrm{AM}\end{array}$ & $\begin{array}{c}12 \text { noon - } \\
2 \text { PM }\end{array}$ & $\begin{array}{c}4 P M- \\
6 P M\end{array}$ & $\begin{array}{l}8 P M- \\
10 P M\end{array}$ & $\begin{array}{c}10 \mathrm{PM}- \\
11 \mathrm{PM}\end{array}$ \\
\hline \multirow{12}{*}{ Weekday } & \multirow{6}{*}{ East } & Valley College & $0 \%$ & $0 \%$ & $0 \%$ & $0 \%$ & $0 \%$ & $37 \%$ & $19 \%$ & $42 \%$ & $54 \%$ & $58 \%$ \\
\hline & & Van Nuys & $4 \%$ & $7 \%$ & $0 \%$ & & & $38 \%$ & $56 \%$ & $57 \%$ & & \\
\hline & & Sepulveda & $0 \%$ & $8 \%$ & $0 \%$ & $14 \%$ & $0 \%$ & $33 \%$ & $56 \%$ & $48 \%$ & $57 \%$ & $33 \%$ \\
\hline & & Reseda & $0 \%$ & & $4 \%$ & $22 \%$ & $0 \%$ & $29 \%$ & & $40 \%$ & $67 \%$ & $33 \%$ \\
\hline & & Pierce College & $0 \%$ & $0 \%$ & $3 \%$ & $25 \%$ & $0 \%$ & $18 \%$ & $43 \%$ & $52 \%$ & $83 \%$ & $67 \%$ \\
\hline & & Chatsworth & $0 \%$ & $0 \%$ & $0 \%$ & $0 \%$ & $0 \%$ & $4 \%$ & $33 \%$ & $15 \%$ & $17 \%$ & $22 \%$ \\
\hline & \multirow{6}{*}{ West } & North Hollywood & $0 \%$ & $7 \%$ & $15 \%$ & $11 \%$ & $0 \%$ & $26 \%$ & $36 \%$ & $63 \%$ & $59 \%$ & $58 \%$ \\
\hline & & Valley College & $0 \%$ & $0 \%$ & $0 \%$ & $0 \%$ & $25 \%$ & $37 \%$ & $42 \%$ & $31 \%$ & $63 \%$ & $67 \%$ \\
\hline & & Van Nuys & $4 \%$ & $0 \%$ & $0 \%$ & & & $35 \%$ & $40 \%$ & $52 \%$ & & \\
\hline & & Sepulveda & $0 \%$ & $0 \%$ & $0 \%$ & $0 \%$ & $0 \%$ & $40 \%$ & $43 \%$ & $35 \%$ & $48 \%$ & $40 \%$ \\
\hline & & Reseda & $0 \%$ & & $0 \%$ & $0 \%$ & $25 \%$ & $41 \%$ & & $28 \%$ & $23 \%$ & $42 \%$ \\
\hline & & Pierce College & $0 \%$ & $7 \%$ & $0 \%$ & $0 \%$ & $0 \%$ & $49 \%$ & $31 \%$ & $26 \%$ & $42 \%$ & $27 \%$ \\
\hline \multirow{10}{*}{ Weekend } & \multirow{5}{*}{ East } & Valley College & $0 \%$ & $8 \%$ & & $0 \%$ & $0 \%$ & $67 \%$ & $67 \%$ & & $25 \%$ & $67 \%$ \\
\hline & & Van Nuys & $0 \%$ & $33 \%$ & $18 \%$ & $0 \%$ & & $43 \%$ & $89 \%$ & $58 \%$ & $71 \%$ & \\
\hline & & Reseda & $0 \%$ & $0 \%$ & $0 \%$ & $13 \%$ & $33 \%$ & $39 \%$ & $36 \%$ & $42 \%$ & $46 \%$ & $78 \%$ \\
\hline & & Pierce College & $18 \%$ & $0 \%$ & $9 \%$ & $0 \%$ & $0 \%$ & $33 \%$ & $43 \%$ & $45 \%$ & $38 \%$ & $67 \%$ \\
\hline & & Chatsworth & $33 \%$ & $0 \%$ & $0 \%$ & $0 \%$ & $0 \%$ & $33 \%$ & $44 \%$ & $28 \%$ & $10 \%$ & $11 \%$ \\
\hline & \multirow{5}{*}{ West } & North Hollywood & $20 \%$ & $17 \%$ & $0 \%$ & $38 \%$ & $0 \%$ & $70 \%$ & $58 \%$ & $44 \%$ & $67 \%$ & $33 \%$ \\
\hline & & Valley College & $0 \%$ & $8 \%$ & $0 \%$ & $0 \%$ & $0 \%$ & $37 \%$ & $50 \%$ & $44 \%$ & $38 \%$ & $33 \%$ \\
\hline & & Van Nuys & $0 \%$ & $0 \%$ & $0 \%$ & $0 \%$ & & $48 \%$ & $64 \%$ & $45 \%$ & $8 \%$ & \\
\hline & & Reseda & $0 \%$ & $0 \%$ & $0 \%$ & $0 \%$ & $0 \%$ & $26 \%$ & $33 \%$ & $33 \%$ & $30 \%$ & $58 \%$ \\
\hline & & Pierce College & $0 \%$ & $0 \%$ & $0 \%$ & $0 \%$ & $0 \%$ & $41 \%$ & $25 \%$ & $42 \%$ & $29 \%$ & $27 \%$ \\
\hline
\end{tabular}


On weekdays, no more than 25 percent of buses strand a cyclist during any time period. However, these high rates occur during the night and night-time period, suggesting that CTU travel behavior may not match the overall service levels suggested by pedestrian ridership. Also, the stations that hit these high numbers are the Valley College, Reseda, and Pierce College stations, all of which are near large colleges, suggesting that students taking evening classes are being left behind. This is corroborated by the highest slot full on departure occurring at the college stations at the night and late-night periods, with the Pierce College station at night having the maximum value of 83 percent full. The other station of note is the North Hollywood station, at which a cyclist most likely will need to wait for the next bus, regardless of the time of day. North Hollywood is a busy station because it connects with the northern terminus of the Red Line (subway).

On weekends, the patterns change. During the morning and lunch periods, cyclists are left behind, with Chatsworth and Van Nuys having 33 percent of the stranded cyclists, presumably because of increased recreational riding of bicycles. In fact, the percentages of slots full reached a maximum of 89 percent at the Van Nuys station during the lunch period. These high levels also suggest that CTU usage is not consistent with Orange Line service levels, which more closely match pedestrian usage levels.

\section{Cyclist Ridership vs. Pedestrian Ridership}

Typically, when transit agencies determine ridership levels, they collect data for peak hours and interpolate usage for the other time periods (Hummer 1994). This means that CTU estimates would be based on peak morning, lunch, and afternoon rush-hour periods, which may or may not coincide with peak CTU usage. By comparing pedestrian and CTU usage data collected in this study, we can determine if peak-hour testing is adequate to identifying stranded cyclist issues.

To evaluate if CTUs have similar use patterns as pedestrians, pedestrian user data were obtained from Metro, whose daily data is reported for five time periods: morning (5-9 AM), business hours (9 AM-3 PM), afternoon rush hour (3-7 PM), night (7 PM-12 midnight), and overnight (12 midnight-5 AM). Metro's overnight period is excluded because CTU ridership data were not collected during this time period. The pedestrian data used are an average of the October to December 2013 daily data. In Tables 3 and 4, pedestrian data were adjusted as a percent of time represented to be comparable to the bike data collected. Table 3 shows the stations at which longer time periods were kept, and Table 4 shows two-hour intervals (except the night period, which is three hours).

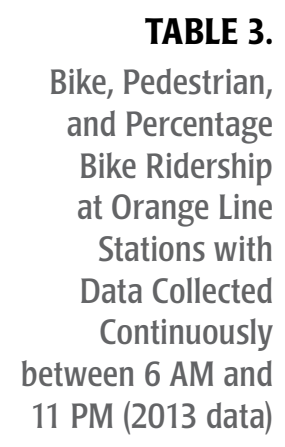

\begin{tabular}{|c|c|c|c|c|c|c|c|c|c|c|c|c|}
\hline \multirow{3}{*}{ Time Period } & \multirow{2}{*}{\multicolumn{3}{|c|}{$\begin{array}{c}\text { Weekday } \\
\text { West }\end{array}$}} & \multicolumn{9}{|c|}{ Weekend } \\
\hline & & & & \multicolumn{3}{|c|}{ East } & \multicolumn{6}{|c|}{ West } \\
\hline & Bike & Ped & $\%$ Bike & Bike & Ped & $\%$ Bike & Bike & Ped & $\%$ Bike & Bike & Ped & $\%$ Bike \\
\hline $6 \mathrm{AM}-9 \mathrm{AM}$ & 40 & 1,201 & $3.3 \%$ & 24 & 467 & $5.1 \%$ & 30 & 396 & $7.6 \%$ & 24 & 329 & $7.3 \%$ \\
\hline 3 PM-7 PM & 74 & 2,450 & $3.0 \%$ & 39 & 1,124 & $3.5 \%$ & 36 & 1,223 & $2.9 \%$ & 25 & 839 & $3.0 \%$ \\
\hline 7 PM-11 PM & 39 & 892 & $4.4 \%$ & 21 & 344 & $6.1 \%$ & 32 & 696 & $4.6 \%$ & 13 & 393 & $3.3 \%$ \\
\hline Chi-Square & 11.211 & $* *$ & & 4.83 & & & 14.434 & $* * *$ & & 19.333 & $* * *$ & \\
\hline
\end{tabular}

Note: Chi-square Significance at * 0.10 level, ${ }^{* *} 0.05$ level, ${ }^{* * *} 0.01$ level; otherwise not statistically significant 
TABLE 4. Bike, Pedestrian, and Percentage Bike Ridership at Orange Line Stations with Data Collected for Four Standard Time Periods (2013 data)

\begin{tabular}{|c|c|c|c|c|c|c|c|c|c|c|c|c|c|c|c|}
\hline \multirow{3}{*}{ Time Period } & \multicolumn{12}{|c|}{ Weekday - East } & & & \\
\hline & \multicolumn{3}{|c|}{ Chatsworth } & \multicolumn{3}{|c|}{ Pierce College } & \multicolumn{3}{|c|}{ Sepulveda } & \multicolumn{3}{|c|}{ Valley College } & & & \\
\hline & Bike & Ped & $\%$ Bike & Bike & Ped & $\%$ Bike & Bike & Ped & $\%$ Bike & Bike & Ped & $\%$ Bike & & & \\
\hline $6 \mathrm{AM}-8 \mathrm{AM}$ & 2 & 98 & $2.0 \%$ & 16 & 476 & $3.4 \%$ & 29 & 895 & $3.2 \%$ & 33 & 1,008 & $3.3 \%$ & & & \\
\hline 12 noon-2 PM & 8 & 72 & $11.1 \%$ & 18 & 457 & $3.9 \%$ & 20 & 698 & $2.9 \%$ & 8 & 817 & $1.0 \%$ & & & \\
\hline 4PM-6PM & 8 & 149 & $5.4 \%$ & 47 & 702 & $6.7 \%$ & 43 & 1,095 & $3.9 \%$ & 38 & 1,163 & $3.3 \%$ & & & \\
\hline 8 PM-11 PM & 5 & 50 & $10.0 \%$ & 26 & 302 & $8.6 \%$ & 16 & 430 & $3.7 \%$ & 20 & 484 & $4.1 \%$ & & & \\
\hline \multirow{4}{*}{ Chi-Square } & 6.39 & * & & 12.33 & $* * *$ & & 1.56 & & & 13.91 & $* * *$ & & & & \\
\hline & \multicolumn{12}{|c|}{ Weekday - West } & & & \\
\hline & \multicolumn{3}{|c|}{ North Hollywood } & \multicolumn{3}{|c|}{ Valley College } & \multicolumn{3}{|c|}{ Sepulveda } & \multicolumn{3}{|c|}{ Pierce College } & & & \\
\hline & Bike & Ped & $\%$ Bike & Bike & Ped & $\%$ Bike & Bike & Ped & $\%$ Bike & Bike & Ped & $\%$ Bike & & & \\
\hline $6 \mathrm{AM}-8 \mathrm{AM}$ & 25 & 801 & $3.1 \%$ & 32 & 794 & $4.0 \%$ & 32 & 878 & $3.6 \%$ & 35 & 374 & $9.4 \%$ & & & \\
\hline 12 noon-2 PM & 16 & 668 & $2.4 \%$ & 19 & 716 & $2.7 \%$ & 18 & 564 & $3.2 \%$ & 14 & 332 & $4.2 \%$ & & & \\
\hline 4PM-6PM & 51 & 1,225 & $4.2 \%$ & 24 & 1,221 & $2.0 \%$ & 28 & 882 & $3.2 \%$ & 20 & 516 & $3.9 \%$ & & & \\
\hline $8 \mathrm{PM}-11 \mathrm{PM}$ & 23 & 669 & $3.4 \%$ & 25 & 702 & $3.6 \%$ & 19 & 496 & $3.8 \%$ & 18 & 294 & $6.1 \%$ & & & \\
\hline \multirow[t]{4}{*}{ Chi-Square } & 4.11 & & & 8.10 & $* *$ & & 0.59 & & & 12.17 & $* * *$ & & & & \\
\hline & \multicolumn{12}{|c|}{ Weekend - East } & & & \\
\hline & \multicolumn{3}{|c|}{ Chatsworth } & \multicolumn{3}{|c|}{ Pierce College } & \multicolumn{3}{|c|}{ Reseda } & \multicolumn{3}{|c|}{ VanNuys } & & & \\
\hline & Bike & Ped & $\%$ Bike & Bike & Ped & \% Bike & Bike & Ped & \% Bike & Bike & Ped & $\%$ Bike & & & \\
\hline $6 \mathrm{AM}-8 \mathrm{AM}$ & 6 & 23 & $26.1 \%$ & 11 & 137 & $8.0 \%$ & 13 & 193 & $6.7 \%$ & 13 & 312 & $4.2 \%$ & & & \\
\hline 12 noon- 2 PM & 8 & 45 & $17.8 \%$ & 13 & 231 & $5.6 \%$ & 15 & 338 & $4.4 \%$ & 32 & 561 & $5.7 \%$ & & & \\
\hline 4PM-6PM & 5 & 49 & $10.2 \%$ & 15 & 291 & $5.2 \%$ & 14 & 360 & $3.9 \%$ & 19 & 562 & $3.4 \%$ & & & \\
\hline 8 PM-11 PM & 3 & 44 & $6.8 \%$ & 15 & 216 & $6.9 \%$ & 18 & 165 & $10.9 \%$ & 15 & 229 & $6.6 \%$ & & & \\
\hline \multirow[t]{4}{*}{ Chi-Square } & 4.34 & & & 1.47 & & & 10.35 & $* *$ & & 4.85 & & & & & \\
\hline & \multicolumn{15}{|c|}{ Weekend - West } \\
\hline & \multicolumn{3}{|c|}{ North Hollywood } & \multicolumn{3}{|c|}{ Valley College } & \multicolumn{3}{|c|}{ VanNuys } & \multicolumn{3}{|c|}{ Reseda } & \multicolumn{3}{|c|}{ Pierce College } \\
\hline & Bike & Ped & $\%$ Bike & Bike & Ped & $\%$ Bike & Bike & Ped & \% Bike & Bike & Ped & $\%$ Bike & Bike & Ped & $\%$ Bike \\
\hline $6 \mathrm{AM}-8 \mathrm{AM}$ & 21 & 264 & $8.0 \%$ & 10 & 235 & $4.3 \%$ & 13 & 219 & $5.9 \%$ & 7 & 142 & $4.9 \%$ & 11 & 112 & $9.8 \%$ \\
\hline 12 noon -2 PM & 21 & 458 & $4.6 \%$ & 18 & 454 & $4.0 \%$ & 23 & 350 & $6.6 \%$ & 12 & 255 & $4.7 \%$ & 9 & 203 & $4.4 \%$ \\
\hline 4PM-6 PM & 16 & 611 & $2.6 \%$ & 16 & 584 & $2.7 \%$ & 15 & 420 & $3.6 \%$ & 12 & 275 & $4.4 \%$ & 5 & 235 & $2.1 \%$ \\
\hline $8 \mathrm{PM}-11 \mathrm{PM}$ & 20 & 522 & $3.8 \%$ & 13 & 197 & $6.6 \%$ & 2 & 262 & $0.8 \%$ & 15 & 225 & $6.7 \%$ & 11 & 200 & $5.5 \%$ \\
\hline Chi-Square & 12.06 & $* * *$ & & 5.52 & & & 13.46 & $* * *$ & & 1.37 & & & 9.03 & $* *$ & \\
\hline
\end{tabular}

Note: Chi-square Significance at ${ }^{*} 0.10$ level, ${ }^{* *} 0.05$ level, ${ }^{* * *} 0.01$ level; otherwise not statistically significant 
Table 4 shows more stations but with data collected for fewer hours during each day. In this case, the westbound ridership behavior of cyclists and pedestrians from North Hollywood is statistically equivalent. However, what can be observed is that the statistically significant patterns occur at the Pierce and Valley College stations, both east and westbound, with higher evening and morning ridership levels. Student evening cycle ridership seems to be higher. However, on the weekends, in either direction, the statistically-significant ridership distribution occurs with an increase in morning ridership, most likely a reflection of increased recreational ridership. There are also higher evening ridership levels, perhaps an indicator of the invisible riders who need to use bicycles for the last mile due to reduced weekend bus service. The Chatsworth station has very high CTU percentages, a reflection of the low pedestrian ridership levels at this suburban terminus. The area is immediately surrounded by industrial uses, so most users are likely to either come via car, transit, or bicycle. With reduced car commuters on weekends, the overall usage at this station declines.

The results suggest that transit agencies should more closely monitor cyclist behavior in the mornings and evenings when there are higher percentages of CTUs but generally lower pedestrian ridership levels, the usual indicator for decreased service levels. To minimize monitoring, a transit agency can start by monitoring at colleges and at stations that are highly industrial to determine if there is an issue.

\section{Effects of Increased Evening Service Levels}

Between 2012 and 2013, the evening Orange Line service increased from three buses per hour to four buses per hour (see Table 5). The number of eastbound cyclists decreased from 53 to 47, and the westbound cyclists increased from 34 to 51. Overall, CTU usage increased at all stations except two: eastbound Sepulveda and Reseda. CTUs at these stations found that 100 percent of the slots were full and appear to have changed their transit behavior. There is a statistically-significant drop in the percentage of eastbound buses that strand a cyclist (paired- $t=6.657, \mathrm{p}=0.022, \mathrm{df}=2$ ) and almost significant considering both directions (paired- $t=2.343, p=0.058, d f=6$ ). The question is, how much of the change in the percentage of stranded cyclists is due to change in cyclist ridership levels and how much is due to the increased bus service?

TABLE 5. Comparison of 2012 and 2013 Bike Data to Understand Effects of Increased Night Service

\begin{tabular}{|c|c|c|c|c|c|c|c|c|c|c|c|c|}
\hline \multirow{2}{*}{ Direction } & \multirow{2}{*}{ Station } & \multicolumn{2}{|c|}{$\begin{array}{l}\text { Total } \\
\text { Buses } \\
\end{array}$} & \multicolumn{2}{|c|}{$\begin{array}{l}\text { Bikes Leaving } \\
\text { Station }\end{array}$} & \multicolumn{2}{|c|}{$\begin{array}{l}\text { Percent } \\
\text { Slots Full }\end{array}$} & \multicolumn{3}{|c|}{$\begin{array}{l}\text { Percent Buses } \\
\text { Stranding a Cyclist }\end{array}$} & \multicolumn{2}{|c|}{ Change in Percent Stranded } \\
\hline & & 2012 & 2013 & 2012 & 2013 & 2012 & 2013 & 2012 & Model & 2013 & $\begin{array}{l}\text { Due to } \\
\text { Ridership }\end{array}$ & $\begin{array}{c}\text { Due to Increased } \\
\text { Service }\end{array}$ \\
\hline \multirow{3}{*}{ East } & Sepulveda & 6 & 7 & 18 & 13 & $100 \%$ & $62 \%$ & $67 \%$ & $21 \%$ & $14 \%$ & $-45 \%$ & $-7 \%$ \\
\hline & Reseda & 6 & 8 & 18 & 16 & $100 \%$ & $67 \%$ & $100 \%$ & $54 \%$ & $25 \%$ & $-46 \%$ & $-29 \%$ \\
\hline & Pierce College & 7 & 8 & 17 & 18 & $81 \%$ & $75 \%$ & $71 \%$ & $46 \%$ & $25 \%$ & $-25 \%$ & $-21 \%$ \\
\hline \multirow{4}{*}{ West } & North Hollywood & 7 & 8 & 16 & 19 & $76 \%$ & $79 \%$ & $29 \%$ & $32 \%$ & $13 \%$ & $4 \%$ & $-20 \%$ \\
\hline & Sepulveda & 7 & 8 & 9 & 12 & $43 \%$ & $50 \%$ & $0 \%$ & $4 \%$ & $0 \%$ & $4 \%$ & $-4 \%$ \\
\hline & Reseda & 6 & 9 & 5 & 8 & $28 \%$ & $30 \%$ & $0 \%$ & $0 \%$ & $0 \%$ & $0 \%$ & $0 \%$ \\
\hline & Pierce College & 5 & 8 & 4 & 12 & $27 \%$ & $50 \%$ & $0 \%$ & $0 \%$ & $0 \%$ & $0 \%$ & $0 \%$ \\
\hline
\end{tabular}


To answer this question, a model was designed that started with the 2013 raw data and estimated the number of buses that would strand a cyclist, assuming the 2012 bus level had occurred instead. Because the order of the buses was known for 2013, the riders on the skipped bus were assigned to the next bus (both the cyclists arriving via the bus and those wanting to board) and are left in the queue until enough open slots are available. Table 5 shows that the significant reduction in stranded cyclists was due to fewer cyclists using the Orange Line. However, it also shows that the increased service reduced stranded cyclists by up to 29 percent. With the reduced stranded cyclists in 2013, it would be interesting to see if eastbound ridership increased in 2014.

\section{How Full is Too Full?}

The final question is determining if there is a rule of thumb on when the bike racks are so full that cyclists are consistently being stranded. The 2012 and 2013 data for each station, time period, direction, and day of the week were used to compare the percentage of slots full on the bus bicycle racks and the percentage of buses that stranded a cyclist. Figure 3 shows that whereas bus rack utilization can be as high as 70 percent and still have no stranded cyclists, it is still possible for 33 percent of buses to strand cyclists with the rack utilization rate only being 33 percent.

FIGURE 3.

Percentage of buses stranding cyclists vs. bike rack utilization for all Orange Line stops with complete 2-hour periods for 2012 and 2013

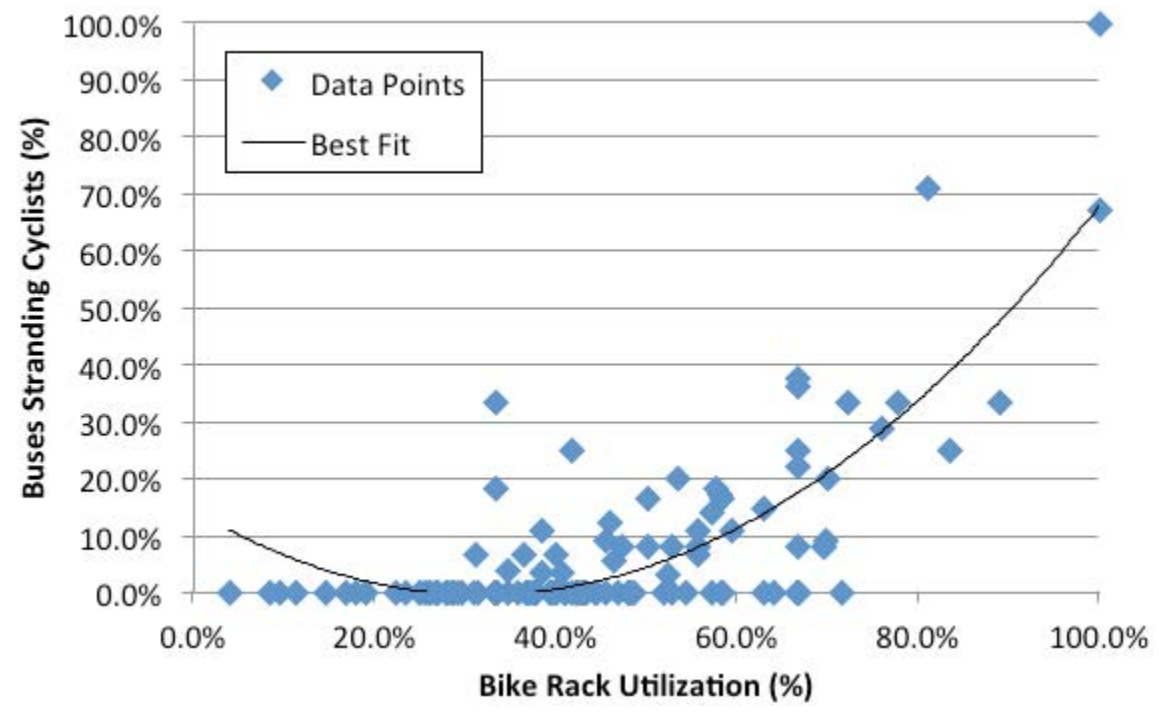

Running Ordinary Least Square regression on these data indicates that a quadratic model is a better fit than the linear model and supports the assertion that a greater number of cyclists will be stranded as bus bicycle rack utilization increases (see Table 6). Tobit model regressions to account for censored data actually produced lower R-squared values, and creating an exponential model is mathematically infeasible due to the inability to take the logarithm of 0 (the lowest and most frequent percentage of the people left behind). Based on the best-fit equation, a bike rack utilization rate of 69 percent leads to 20 percent of buses stranding a cyclist. 
TABLE 6.

Regression Results for Modeling Percentage of Buses Stranded Using Linear and Quadratic Models

\begin{tabular}{|l|r|r|r|r|r|r|}
\cline { 2 - 7 } \multicolumn{1}{c|}{} & Coefficient & t-Stat & P-value & Coefficient & t-Stat & P-value \\
\hline Intercept & -0.167 & -6.211 & $<.001$ & 0.143 & 3.470111 & 0.001 \\
\hline$\%$ Slots full & 0.522 & 9.4497 & $<.001$ & -0.930 & -5.42812 & $<.001$ \\
\hline (\% Slots full)^2 & & & & 1.465 & 8.767103 & $<.001$ \\
\hline F & 89.296 & & & 109.336 & & \\
\hline Significance F & $<.001$ & & & $<.001$ & & \\
\hline $\mathrm{n}$ & 131 & & & 131 & & \\
\hline R-squared & 0.409 & & & 0.631 & & \\
\hline Adj R-squared & 0.404 & & & 0.625 & & \\
\hline
\end{tabular}

\section{Conclusions and Recommendations}

The literature has shown that CTUs prefer to bring their bicycles with them on public transit rather than leave them at bicycle racks at transit stations (Bachand-Marieau et al. 2011). Metro, the operator of the Los Angeles Orange Line, has implemented policies to accommodate those CTU preferences by having exterior vehicle racks so that the bus interiors are not too full. In the summer of 2013, Metro also increased its evening service on the Orange Line to help decrease the number of stranded cyclists. This study has three main findings.

First, cyclist behavior is indeed different than pedestrian behavior. CTUs are more likely to use the Orange Line during weekday evenings at the Valley College and Pierce College stations, suggesting that the influx is due to students attending evening classes. It is possible that evening ridership is higher because bus service is less frequent, making the last mile more difficult to connect and increasing the viability of bicycles. Also, automobile traffic is lighter during the evenings, making it safer to use bicycles to finish the last mile. Unfortunately, we can only surmise these postulations as the data collected does not directly address these issues. CTU behavior is not the same as pedestrian transit user behavior, so we recommend counting CTUs during weekday evening hours near college campuses, as they are more likely to be a location with stranded cyclists.

On weekends, the mornings and early afternoons are more used by cyclists, most likely a reflection of weekend recreational cycling, especially considering the Orange Line has a Class I bicycle path paralleling it. Weekends are also a period of increased non-commuting trips, and Bachand-Marieau et al. (2011) found that CTUs who are regular commuters are more willing to leave their bicycles at a station, whereas CTUs on irregular trips, such as shopping and visiting, prefer to take their bicycles with them. The higher weekend usage also may be due to changes in trip purpose. We recommend that transit agencies count cyclist behavior during weekend mornings because of recreational cyclists influencing CTU ridership levels.

Second, increased evening service reduced the number of stranded cyclists. Because Metro cannot readily increase on-vehicle bicycle storage due to length limitations and crowded buses, it added an extra bus per hour in 2013. The extra service decreased the number of stranded cyclists, but not after losing some CTU ridership that was a response to the high probability of being left behind in 2012 in the eastbound direction. The west- 
bound service did not have a stranded cyclist problem and saw an increase in usage levels. With fewer stranded in the eastbound direction as of 2013, CTU usage may increase. Increased service levels will continue to decrease the number of stranded cyclists, but it is an expensive fix. An alternative would be to find a method to engineer a bike rack onto the back of the Orange Line bus; however, both design considerations and legal restrictions limiting vehicle length would need to be addressed.

Third, a more generalized exponential trend occurs between the percentage of full bike racks and the number of buses stranding cyclists. Performing this study required many hours of data collection to monitor who is left behind at a station. Although the Greater Cleveland Regional Transit Authority is the only agency that collects bike rack loadings with detailed information including time, bus line, and location, it does not count cyclists left behind (Flamm 2013). Our data show a quadratic relationship between the percentage of full racks during a time period and the percentage of buses that strand a cyclist. Although it is difficult to generalize to a rule of thumb, it might be reasonable to assume that if there is normally a 66 percent rate of full racks, there should be less than 20 percent of the buses stranding a cyclist. But if two of the three racks are normally full, with occasionally all the racks full, then there should be consideration of increasing on-vehicle bicycle storage or increasing service levels.

A better understanding of cyclist choice behavior also would be beneficial. This would require interviews and surveys to determine when cyclists choose to use their bicycles and why. It could answer questions on what they do if they are stranded and at what level do they reach a point where they shift to an all-bicycle mode because of being stranded. Understanding the demographics of users could answer how many are part of the "invisible riders" and how many are represented by cycling advocates. They also may generate ideas on how to increase the desirability of using station bike racks. Providing space for cyclists aboard transit is difficult, and the Metro Orange Line successfully did so with its increase in evening service during the summer of 2013.

\section{Acknowledgments}

This research was funded by a California State University, Northridge, College of Social and Behavioral Sciences research grant. Several other trained students help collect data: Kimberly Anderson, Larry Jenkins, Jinmi Salazar, and Marisol Zamar.

\section{References}

Bachand-Marleau, Julie, Jacob Larsen, and Ahmed M. El-Geneidy. 2011. Much anticipated marriage of cycling and transit: How will it work? Transportation Research Record 2247: 109-117.

Bergman, Asa, John Gliebe, and James Strathman. 2011. Modeling access mode choice for inter-suburban commuter rail. Journal of Public Transportation 14(4): 23-42.

Cervero, Robert, Benjamin Caldwell, and Jesus Cuellar. 2013. Bike-and-Ride: Built it and they will come. Journal of Public Transportation 16(4): 83-105. 
Duarte, Fabio, and Fernando Rojas. 2012. Intermodal connectivity to BRT: A comparative analysis of Bogota and Curitiba. Journal of Public Transportation 15(2): 1-18.

Flamm, Bradley J. 2013. Determinants of bicycle-on-bus-boardings: A case study of the Greater Cleveland RTA. Journal of Public Transportation 16(2): 67-84.

Hagelin, C. A. 2005. A return on investment analysis of bikes-on-bus programs. University of South Florida: National Center for Transit Research 576-05, FDOT BD549-04.

Hensher, H. A., and G. F. Thomas. 2008. Bus rapid transit systems: A comparative assessment. Transportation 35: 501-518.

Hine, J. P., and J. Scott. 2000. Seamless accessible travel: Users' views of the public transport journey and interchange. Transport Policy 7(3): 217-226.

Hummer, Joseph E. 1994. Public transportation studies. In Robertson, H. D., J. E. Hummer, and D. C. Nelson (eds.), Manual of Transportation Engineering Studies. Englewood Cliffs, NJ: Prentice-Hall.

Koeppel, D. 2006. Invisible riders. Bicycling. Retrieved from http://www.utne.com/200607-01/InvisibleRiders.aspx.

Krizek, Kevin J., Eric W. Stonebraker. 2010. Bicycling and transit: A marriage unrealized. Transportation Research Record 2144: 161-167.

Krizek, Kevin J., Eric Stonebraker, and Seth Tribbey. 2011. Bicycle access and egress to transit: Informing the possibilities. San Jose, CA: Mineta Transportation Institute, San Jose State University.

Martens, Karel. 2004. The bicycle as a feedering mode: Experiences from three European countries. Transportation Research D 9(4): 281-294.

Pucher, John, and Ralph Buehler. 2009. Integrating bicycling and public transport in North America. Journal of Public Transportation 12(3): 79-104.

U.S. Department of Education, National Center for Education Statistics. 2013. Integrated Postsecondary Education Data System (IPEDS), Fall Enrollment Survey (IPEDS-EF:90), Spring 2001 through Spring 2012, Enrollment and Finance components, and Fall 2011, Completions component. Retrieved from http://nces.ed.gov/programs/digest/d12/ tables/dt12_277.asp?referrer=list.

Vincent, William, and Lisa Callaghan. 2007. A preliminary evaluation of the Metro Orange Line bus rapid transit project. Transportation Research Record 2034: 37-44.

Vincent, William, and Lisa Callaghan Jerram. 2006. The potential for Bus Rapid Transit to reduce transportation-related $\mathrm{CO}_{2}$ emissions. Journal of Public Transportation 9(3): 219-237.

Wang, Rui, and Chen Liu. 2013. Bicycle-transit integration in the United States, 20012009. Journal of Public Transportation 16(3): 95-119.

Wener, Richard E., and Gary W. Evans. 2007. A morning stroll: Levels of physical activity in car and mass transit commuting. Environment and Behavior 39(1): 62-74. 


\section{About the Authors}

CRAIG T. Olwert (craig.olwert@csun.edu) is an Assistant Professor of Urban Studies and Planning at California State University, Northridge, where he conducts research on sustainability, transit-oriented development, economic development, and retail planning.

JOSE TCHOPOURIAN (jose.tchopourian@lacity.org) is a transportation planner for the Los Angeles Department of Transportation involved with the Active Transportation Division working on bicycle and pedestrian programs.

Vicente O. Arellano (vicente.arellano.786@my.csun.edu) is a student at California State University, Northridge, with research interests in sustainability, transit-oriented development, and planning theory.

Mintesnot G. WoldeAmanUel (mintesnot.woldeamanuel@csun.edu) is an Associate Professor of Urban Studies and Planning at California State University, Northridge, where he conducts research on transportation planning and multimodal travel. 